Revista Vernáculo, no 14 - 15 - 16, pp. 51 - 63.

\title{
FASCISMO E IGREJA CATÓLICA
}

Bruno Quadros e Quadros ${ }^{1}$

Resumo: O presente artigo tem como tema a articulação política entre o fascismo e a Igreja católica. Como se deu a relação entre os regimes totalitários de direita, predominantes na Europa dos anos 20,30 e 40 e a Igreja católica é o eixo central do artigo que ora se apresenta. Será dado um tratamento mais profundo aos casos da Espanha e da Itália, onde essa relação foi mais estreita. Não deixarão de ser abordados outros países onde há uma grande população católica, nos quais foi possível uma maior influência do Vaticano, nomeadamente Portugal, Croácia e Áustria, além daqueles que foram ocupados durante a Segunda Guerra Mundial. Além disso, serão tratados também movimentos fascistas que não conseguiram chegar ao poder mas que mostram o apelo ao catolicismo, como o integralismo no Brasil e o rexismo na Bélgica.

Palavras-chave: Fascismo, Igreja católica, Vaticano, totalitarismo, franquismo, salazarismo, integralismo.

\section{INTRODUÇÃO}

A Europa pós-1918 apresentava-se como um continente destruído: nações inteiras arrasadas, milhões de mortos, feridos e refugiados, economias em frangalhos e sociedades desorganizadas. Tais conseqüências da Primeira Guerra Mundial ocasionaram o recrudescimento de ressentimentos, nacionalismos e chauvinismos entre vitoriosos e derrotados, além de ser um pano de fundo extremamente fértil para a radicalização política, tanto à direita quanto à esquerda.

A ascensão dos regimes de extrema-direita na Europa, durante os anos 20 e 30, está relacionada a esta radicalização e tem como um dos seus maiores sustentáculos a Igreja, junto com os grandes proprietários de terras e industriais, que compartilhavam com os fascistas o anticomunismo militante. Para eles, somente um sistema político antiliberal e totalitário poderia salvaguardá-los da influência dos "vermelhos ateus".

\footnotetext{
${ }^{1}$ Graduando do curso de História da Universidade Federal do Paraná (UFPR) e Graduando do curso de Relações Internacionais das Faculdades Integradas Curitiba (FIC).
} 
Deixamos de abordar a Alemanha nazista porque, apesar de significativa população católica, este país tem maioria protestante e por conseguinte a Igreja católica tem sua influência eclipsada pela da Igreja protestante. Outro fator que influenciou nesta decisão é a farta bibliografia existente sobre a relação EstadoIgreja durante o nazismo ${ }^{2}$.

Por último há de ser observado o fato de a relação entre o Estado fascista e a Igreja ter se dado em graus e formas diferenciados conforme o país analisado e por isso trataremos cada caso separadamente.

\section{A ESPANHA FRANQUISTA}

\subsection{A tradição católica}

A forte tradição católica presente na península Ibérica remonta à resistência à expansão moura ${ }^{3}$, na qual o catolicismo constituiu um elemento de unidade e de apego em tempos extremamente adversos, em que a cristandade perdia terreno para os muçulmanos.

No século XV, o catolicismo foi a mola propulsora para a Reconquista, sob a égide dos Reis Católicos, Fernando de Aragão e Isabel de Castela, na qual os muçulmanos foram expulsos e gestou-se o Estado-Nação espanhol. Sob o seu reinado, os judeus foram expulsos da Espanha e foi dado novo ânimo à Inquisição.

O império colonial espanhol exportou para a América a influência que a Igreja tinha em solo metropolitano, sendo a Igreja protagonista na luta entre liberais e conservadores quando da independência das nações latino-americanas.

Durante as Guerras Napoleônicas, os camponeses, organizados em torno de uma fervorosa crença católica, empreenderam operações de guerrilha contra as tropas francesas que haviam ocupado a Espanha no início do século XIX.

\footnotetext{
${ }^{2}$ A este respeito recomenda-se a leitura de CORNWELL, John. O Papa de Hitler. 1.ed. Rio de Janeiro: Imago, 2000

${ }^{3}$ Mouro era a denominação dada pelos ibéricos ao povo de religião muçulmana que invadiu a península no século VII
} 


\subsection{A ascensão do franquismo}

Ao contrário dos demais países da Europa ocidental, a Espanha não foi substancialmente influenciada pelos ideais iluministas ${ }^{4}$ e por isso mantinha uma estrutura arcaica, o que impediu uma Revolução Industrial no país e atravancou o seu desenvolvimento econômico.

Além disso, a despeito de não ter participado da Primeira Guerra Mundial, sofria uma grave crise institucional em meados da década de 30, desencadeada por vários fatores: os devastadores efeitos econômicos da Grande Depressão; as reivindicações separatistas de regiões como a Catalunha e o País Basco; a injusta distribuição das terras, com a Igreja concentrando em suas mãos muitos latifúndios; e a ingerência dos militares na política. Esse panorama ocasionou uma radicalização política, sendo formadas duas frentes: a Popular, de esquerda e a Nacional, de direita ${ }^{5}$.

A eclosão da Guerra Civil Espanhola (1936-39) polarizou a luta armada entre os nacionalistas de Franco - que englobavam a Falange, partido político de extrema-direita fundado em 1933; os carlistas, cujo partido, a Comunión Tradicionalista Carlista (CTC), advogava uma monarquia católica autoritária e tinha como lema o dístico Dios, Patria y Rey; as Juntas Ofensivas Nacionales Sindicalistas (JONS) e a Igreja Católica - e os republicanos, compostos por elementos socialistas, anarquistas e pelos integrantes das Brigadas Internacionais (comunistas financiados pela União Soviética).

A carta dos bispos espanhóis, em 1937, apoiando as forças franquistas, e a influência da Asociación Nacional Católica de Propagandistas (ANCP) selaram a aliança da Igreja com o Estado franquista ${ }^{6}$.

O apoio da Igreja ao regime de Franco, em processo de consolidação a partir de 1939, com o fim da Guerra Civil, deveu-se também à sua oposição à Segunda República (1931-36). A falta de sensibilidade dos dirigentes espanhóis da época no trato da reforma religiosa inspirou críticas à República, que era tachada de anticlerical e revanchista.

A Francisco Franco também interessava muito o apoio da Igreja porque, com o país em frangalhos ao fim da Guerra Civil, se fazia necessário ao novo

\footnotetext{
${ }^{4}$ A Igreja teve um papel fundamental em barrar a disseminação do Iluminismo em terras espanholas

${ }^{5}$ FACON, Patrick. Franco: os militares conduzem o general ao poder. História Viva. São Paulo: jun. 2004. p.70-72

${ }^{6}$ Microsoft Corporation: Microsoft Encarta 2003. Redmond, 2002
} 
regime legitimar-se perante a população, através de uma instituição que inspirasse respeito, temor e unidade aos espanhóis.

Por esta razão, em que a Igreja se confundia com o Estado, tendo os clérigos amplo acesso ao aparelho estatal, a relação entre o regime de Franco e a Igreja é constantemente denominada nacionalcatolicismo ou de fascismo clerical. O nacionalcatolicismo caracterizou-se por um controle, com o apoio do Estado, de algumas parcelas da vida política e social espanhola, notadamente a educação e a moral, exercendo uma censura cultural e impondo normas sobre determinados comportamentos sociais. Seu ideário baseia-se nos escritos dos intelectuais tradicionalistas Marcelino Menéndez y Pelayo e Juan Vázquez de Mella, para quem "ser espanhol é ser católico"”.

Com o fim da Segunda Guerra Mundial, a aliança Igreja-Estado estreitou-se ainda mais por dois motivos. O primeiro foi a queda das ditaduras nazi-fascistas da Itália e Alemanha, obrigando Franco a modificar a essência de sua ideologia política, centrando-a cada vez mais em um catolicismo fervoroso. $\mathrm{O}$ segundo foi a Guerra Fria e o temor do comunismo, que levou muitos clérigos a apoiar um regime de força a fim de evitar a influência soviética no país. O medo do comunismo propiciou um contato maior com as alas mais conservadoras do Vaticano através dos Congressos Eucarísticos Internacionais ${ }^{8}$.

É digna de nota a preeminência de uma instituição religiosa sobre o Estado franquista, principalmente durante as décadas de 50 e 60, a Opus Dei, fundada em Madri em 1928 por Josemaría Escrivá de Balaguer, que se juntou aos generais franquistas no final da Guerra Civil. A Opus Dei, durante esse período, chegou mesmo a superar em importância a Falange como maior força política do mosaico ideológico que compunha o partido de Franco, o Movimiento Nacional.

Em 1953, foi assinada uma Concordata que estreitou ainda mais os laços entre o governo e a Igreja.

A partir dos anos 60, Franco passou a adotar uma política modernizante, paulatinamente conduzindo a Espanha de um sistema econômico autárquico modelo que visa ao desenvolvimento de todas as atividades produtivas internamente, ou seja, à auto-suficiência, evitando ao máximo as trocas comerciais com o exterior - a um capitalismo mais desenvolvido. Essa tentativa de auto-suficiência havia deixado marcas desastrosas na economia, obrigando Franco a alterá-la substancialmente, incentivando o aporte de investimentos externos ao país. Essa guinada, que promoveu o crescimento econômico, transformou as antigas estruturas sociais e econômicas, sobre as quais a Igreja se

\footnotetext{
${ }^{7}$ Microsoft Corporation: Microsoft Encarta 2003. Redmond, 2002

${ }^{8}$ TEIXEIRA DA SILVA, 2004, p. 333-334
} 
assentava. Tais mudanças levaram certos setores da Igreja a se desligarem do governo e alguns sacerdotes a se articularem com a oposição política ${ }^{9}$.

Depois disso, a relação entre o Estado franquista e a Igreja católica deixou de ser tão estreita como antes.

A morte de Franco, o alcunhado Caudillo, em 1975, e a subseqüente derrocada de seu regime marcaram o fim dos privilégios legais do catolicismo, que foram definitivamente abolidos com a Constituição de 1978.

\section{A ITÁLIA MUSSOLÍNICA}

\subsection{A influência da Igreja católica}

É desnecessário mencionar a influência exercida pela religião católica e sua Igreja na Itália. Berço do Império Romano, que adotou o catolicismo como religião oficial no século IV, abriga a sede da Igreja, o Vaticano, no centro da capital italiana, Roma.

Ser sede da Igreja católica na Itália foi um fator preponderante para que a península fosse uma das únicas regiões européias a permanecer incólume diante da Reforma Protestante dos séculos XVI e XVII, permanecendo sua população predominantemente católica.

Deste período até 1870 , a despeito de a península Itálica não estar unificada politicamente e de a Itália moderna não ter nascido, a Igreja contribuiu para a conservação de um sentimento de comunidade entre os habitantes da península.

Antes de a Itália ser unificada, os Estados papais controlavam politicamente uma considerável parcela de seu território, sendo tal área anexada ao recém-nascido e reunificado Estado italiano.

\subsection{A subida do fascismo ao poder e sua relação com a Igreja}

O movimento fascista italiano, quando de sua criação em 1919, pregava uma revolução nos costumes da sociedade, aderindo às concepções do futurismo de que a guerra seria a cura para todos os males da Itália. Por conseguinte, os fascistas eram contrários à influência da Igreja católica na manutenção do modo de vida que pretendiam revolucionar. Conforme assinala POULANTZAS, "o

\footnotetext{
${ }^{9}$ Microsoft Corporation: Microsoft Encarta 2003. Redmond, 2002
} 
fascismo italiano apresenta nos seus inícios, mas também depois, tendências anticlericais muito nítidas" $"$.

Em 1922, após a Marcha sobre Roma, o Rei Vittorio Emanuele III encarregou Benito Mussolini de constituir um novo governo, marcando a ascensão do fascismo italiano ao poder.

O início do novo governo caracterizou-se por um relativo distanciamento entre a Igreja e o governo, que era abrandado pelo medo da ameaça comunista, assim como na Espanha. Aproveitando esse temor, Mussolini abandonou algumas de suas posições anticlericais assumidas no início do movimento em 1919 e procurou atribuir ao seu Partido Nacional Fascista (PNF) a imagem de baluarte contra o comunismo ateu com o intuito de aproximar-se ao Vaticano ${ }^{11}$.

Essa guinada na relação com a Igreja ocasionou a proibição por parte do Papa Pio XI, em 1924, de o Partido Popular Italiano, fundado em 1919 pelo padre Luigi Sturzo, de colaborar com o Partido Socialista no ataque ao partido de Mussolini, sendo o PPI dissolvido posteriormente.

Antes das eleições de 1924, aumentou o apoio da Igreja devido a favores concedidos por Mussolini, como o resgate do Banco de Roma e a reforma Gentile (mudança no currículo escolar que implementou o ensino de religião no primário e enfatizou as escolas particulares, esmagadoramente mantidas pela Igreja) ${ }^{12}$.

Em setembro de 1924, ainda na esteira dos acontecimentos que se sucederam à morte do deputado socialista Giacomo Matteotti, assassinado em junho do mesmo ano por esquadristas fascistas, o Papa Pio XI descreveria o fascismo como o "menor dos males".

\subsection{A assinatura do Tratado de Latrão}

A relação entre o Estado fascista italiano e a Igreja católica viu uma melhora ainda mais significativa em 11 de fevereiro de 1929, quando foi assinado o Tratado de Latrão, entre o Duce e Pietro Gasparri, Secretário de Estado da Santa Sé e representante do Papa Pio XI. A assinatura do Tratado foi o resultado de anos de negociações secretas, iniciadas em 1926, entre as duas partes.

O Tratado compreendia o reconhecimento do Estado italiano por parte da Igreja, a criação do Estado da Cidade do Vaticano, diminuto território ao redor

\footnotetext{
${ }^{10}$ POULANTZAS, [1970], p.381

${ }^{11}$ TRENTO, 1986, p.18

${ }^{12}$ TRENTO, 1986, p.26

${ }^{13}$ TRENTO, 1986, p.29
} 
da Basílica de São Pedro e sob a soberania papal, e o estabelecimento de relações diplomáticas entre este Estado e a Itália.

Fazia parte do Tratado também o pagamento de uma indenização aproximadamente 2 bilhões de liras à época - por parte do governo italiano ao Vaticano, como compensação às anexações territoriais realizadas durante a unificação da Itália, em 1870, e à perda do poder temporal do Papa.

Além disso, compunha o Tratado uma concordata que retirava o status laico do Estado italiano, sendo o catolicismo declarado religião oficial do Estado.

Outras importantes disposições do Tratado eram: sacerdotes hereges tornaram-se impossibilitados de exercer alguns direitos civis e de tomar parte no funcionalismo público; o casamento religioso passou a ter validade civil; à cidade de Roma foi dado o status de sagrada; a Ação Católica - liga juvenil da Igreja permaneceu com suas atividades intactas ${ }^{14}$; o Papa comprometeu-se em submeter bispos e arcebispos à aprovação do governo italiano; exigência de juramento de fidelidade ao Estado por parte dos sacerdotes antes de assumirem seus cargos; proibição ao clero de se imiscuir na política; os religiosos não mais precisavam prestar o serviço militar; o Estado pontifício comprometeu-se a permanecer neutro em todos os assuntos internacionais e a abster-se de intervir em qualquer conflito, a não ser que assim seja solicitado pelas partes litigantes.

Ambas as partes obtiveram vantagens com a assinatura do pacto. Mussolini viu sua popularidade ampliada, penetrando em setores nos quais sua influência dependia de uma boa relação com a Igreja católica, e reafirmado seu prestígio na comunidade internacional. O Vaticano por sua vez conseguiu pôr fim ao impasse com a Itália - chamado de Questão Romana e que remontava à década de 1870, quando houve a unificação italiana - e durante o qual o Papa declararase "prisioneiro no Vaticano". Além disso, TRENTO observa que o Vaticano, após Latrão, passou a ser o "único sujeito político durante o fascismo, com relações privilegiadas com o Estado" e logrou manter incólume a sua influência no setor juvenil, através da Ação Católica ${ }^{15}$.

Dias depois de assinado o Tratado, Pio XI referir-se-ia a Mussolini como um homem que "a Providência fez-nos encontrar".

O papel da Igreja no apoio ao fascismo mais uma vez foi demonstrado nas eleições de março de 1929 e revelou-se importante, pois nessa ocasião paróquias mobilizaram-se no coro "pelo Papa e pelo Duce", o que resultou em uma esmagadora vitória para Mussolini (98,4\% de votos favoráveis) $)^{16}$.

\footnotetext{
14 TRENTO, 1986, p.33

15 TRENTO, 1986, p.33

16 TRENTO, 1986, p.34
} 


\subsection{O apoio da Igreja à política exterior expansionista}

A invasão à Etiópia, iniciada em 30 de outubro de 1935 e completada em 5 de maio do ano seguinte com a marcha das tropas italianas sobre Adis-Abeba, representou, de acordo com TRENTO, "o ponto mais alto atingido pelo regime no plano do consenso". A Igreja apoiou a empreitada - algo análogo aconteceria na invasão à Albânia, também em 1936 - porque via nela uma oportunidade de expandir suas atividades missionárias na África Oriental ${ }^{17}$.

\section{O INTEGRALISMO NO BRASIL}

\subsection{O catolicismo no Novo Mundo}

A colonização e o desbravamento do Brasil foram permeados pelo desejo de evangelizar os nativos e de estabelecer o primado católico no Novo Mundo, em territórios que estivessem a salvo da Reforma Protestante, que convulsionava a Europa durante o século XVI. Neste período, aos protestantes era proibido o embarque às colônias na América.

A Igreja sempre desempenhou um papel importante na história do Brasil, constituindo-se em elemento agregador da sociedade e exercendo grande influência especialmente entre a população humilde. O que corrobora essa importância é o fato de o país ter a maior população de fé católica no planeta.

\subsection{A Ação Integralista Brasileira}

A Ação Integralista Brasileira, movimento nacional de nítida inspiração fascista fundado em outubro de 1932 por Plínio Salgado, embora não tenha chegado ao poder, desempenhou um importante papel na política nacional durante os seus cinco anos de duração. Provas disso são o número de filiados - as estimativas gravitam entre 100 mil e 1 milhão de membros - e a eleição de 3 mil vereadores, vinte prefeitos e quatro deputados estaduais no pleito de $1936^{18}$.

Plínio Salgado, na primeira parte do seu Manifesto de Outubro, salienta a visão cristã do movimento, justificando-a como "um pensamento profundamente brasileiro, que vem das raízes cristãs da nossa História e está no

\footnotetext{
${ }^{17}$ TRENTO, 1986, p.63

${ }^{18}$ LUNA, Fernando. Anauê! Livro sobre Ação Integralista Brasileira revela o dia-a-dia do fascismo no país. Veja. São Paulo: 18 nov. 1998. p.108-111
} 
íntimo de todos os corações" e afirma que "Deus dirige o destino dos povos"19. Nesse sentido também é digno de nota o próprio dístico do movimento - Deus, Pátria e Família. Além disso, as cerimônias religiosas envolvendo integralistas seguiam normas estipuladas pela AIB; no casamento somente a noiva estava dispensada da utilização do uniforme verde ${ }^{20}$.

$\mathrm{O}$ integralismo foi acolhido com simpatia por muitos religiosos, entre eles Dom Hélder Câmara, convidado por Plínio Salgado a filiar-se à AIB em 1933 devido ao seu ativismo social no Ceará. Após receber a autorização de seu superior na Arquidiocese, Arcebispo Dom Manuel, Dom Hélder aceitou o convite e tornou-se Secretário de Estudos da AIB no Ceará ${ }^{21}$.

\section{A RELAÇÃO FASCISMO-IGREJA EM OUTROS PAÍSES}

\subsection{Portugal salazarista}

Portugal, pelas mesmas razões que a Espanha, tornou-se um país católico por excelência, disseminando sua orientação religiosa para suas colônias do ultramar, especialmente o Brasil.

A subida de Antônio de Oliveira Salazar ao poder, em 1932, marcou o início do Estado Novo, como é conhecido o Estado fascista português. A exemplo de outros países fascistas, implantou-se uma ditadura totalitária que cerceou as liberdades individuais, prendeu os membros da oposição política (com os préstimos da temida PIDE, Polícia Internacional e de Defesa do Estado, a polícia secreta de Salazar), instituiu a censura, caracterizou-se pelo conservadorismo católico e o nacionalismo.

Salazar tirou proveito da influência da Igreja ao aliar-se a ela, sendo seu ideário fascista constituído por um catolicismo militante, que teve grande influência em suas decisões políticas.

${ }^{19}$ Doutrina Integralista. Disponível em http://www.integralismo.com.br. Acesso em 28 jul. 2005

${ }^{20}$ LUNA, Fernando. Anauê! Livro sobre Ação Integralista Brasileira revela o dia-a-dia do fascismo no país. Veja. São Paulo: 18 nov. 1998. p.108-111

${ }^{21}$ Dom Hélder Câmara. Disponível em http://www.domhelder.com.br. Acesso em 28 jul. 2005 


\subsection{A Áustria de Dollfuss}

A Áustria, foi por séculos, através de seu poderoso Império, guardiã da religião católica, em uma Europa cada vez mais tomada pelo protestantismo, pela ortodoxia e pelo islamismo. Isto fez com que, a despeito de sua ligação com a Alemanha, se mantivesse essencialmente católica.

A ascensão de Engelbert Dollfuss, um religioso de extrema-direita, ao poder em 1932 marcou o início de uma ditadura de inspiração fascista na Áustria. Essa ditadura era muito mais próxima de Mussolini do que de Hitler, o que acabou inspirando a oposição dos nacional-socialistas austríacos, que propunham a união territorial com a Alemanha de Hitler, o Anschluss.

Os governos de Dollfuss, que pregava um renascimento católico no país, e de seu sucessor, Schuschnigg, são conhecidos como Austrofascismo, ou seja, a variante austríaca do fascismo.

O Papa Pio XI havia descrito Dollfuss como "um cristão com um coração enorme... que governa a Áustria, de maneira tão boa, resoluta e cristã. Suas ações são testemunhas de suas visões e convicções católicas. O povo austríaco, nossa amada Áustria, agora tem o governo que merece".

Em julho de 1934, a oposição nazista desembocou no assassinato de Dollfuss, que foi sucedido por Kurt Schuschnigg.

\subsection{Outros casos}

Há outros países em que houve a aproximação entre o fascismo e o catolicismo. Entre os casos mais notáveis estão:

O Estado Independente da Croácia, estabelecido durante a Segunda Guerra Mundial (1941-1945) como um Estado fantoche dos nazistas e dominado pelos ustachi, grupo político fascista que colaborou com Hitler, foi palco de limpezas étnicas contra judeus, ciganos e especialmente sérvios.

Mike Budak, Ministro da Religião do Estado Independente da Croácia, pronunciou-se a respeito em 22 de julho de 1941:

O movimento ustachi é baseado na religião católica. Para as minorias, sérvios, judeus e ciganos, nós temos três milhões de balas. Uma parte dessas minorias já foi eliminada e muitos estão esperando para sê-lo. Alguns serão mandados para a Sérvia e o resto será forçado a se converter ao catolicismo. A nossa nova Croácia será livre de todos os hereges, tornando-se puramente católica para os futuros anos.

Em conformidade com as ameaças de Budak, houve também conversões forçadas, em que tomaram parte vários religiosos, entre eles Miroslav Filipovic, 
um frade franciscano do monastério de Petricevac que aderiu ao Exército ustachi em fevereiro de 1942 em um massacre onde pereceram 2730 sérvios, dentre os quais 500 crianças. Filipovic depois se tornou membro da Ustacha e subseqüentemente foi incumbido da administração do campo de concentração de Jasenovac.

No entanto, há ainda muita polêmica a respeito das verdadeiras relações do Vaticano com a Croácia ustachi e sobre o papel desempenhado por Alojzije Stepinac, arcebispo de Zagreb durante o conflito e que foi beatificado em outubro de 1998 pelo Papa João Paulo II.

A Eslováquia, durante a Segunda Guerra Mundial, foi ocupada por tropas da Alemanha nazista, que instalaram um governo fantoche chefiado pelo monsenhor católico Jozef Tiso. Ele também era comandante da Guarda Hlinka, que usava em seus uniformes a cruz cristã. Neste efêmero regime, membros do clero católico também ocupavam cargos governamentais.

O rexismo, variante belga do fascismo fundada em 1930 por Léon Degrelle, tem o seu nome derivado da expressão latina Christus $\operatorname{Rex}^{22}$. Sua ideologia asseverava a necessidade de purificação moral da sociedade belga em conformidade com os preceitos da Igreja católica, formando uma sociedade corporativa e abolindo a democracia.

Em maior ou menor grau, também podem ser citados como exemplos desta relação amistosa entre fascismo e Igreja a Hungria sob os governos de Miklós Horthy e Ferenc Szálasi e a França de Vichy.

\section{CONCLUSÃO}

A relação entre o Vaticano e os regimes de extrema-direita na Europa na primeira metade do século XX ainda merece ser objeto de muito estudo. Até hoje, é muito discutível a posição de Pio XII a respeito do nazi-fascismo e do Holocausto. Uns dizem que silenciou por simpatia ao fascismo e ao antisemitismo, enquanto outros o defendem afirmando que não se manifestou a fim de evitar represálias por parte dos nazistas, então senhores da Europa.

A atração que o fascismo exercia, em contraposição ao bolchevismo e em certa medida à democracia liberal, se devia justamente ao desencanto com esta última, o que levou muitos europeus a vislumbrar uma nova ordem sóciopolítica mais autoritária e mais à direita do que a democracia.

\footnotetext{
${ }^{22}$ A tradução para o português é Cristo Rei
} 
Os motivos que ocasionaram essa aproximação, citados no início do trabalho, legitimaram muitos dos regimes de direita em que a maioria da população professava o catolicismo.

A relação, por vezes simbiótica, entre o Estado fascista e a Igreja católica provocou um opróbrio depois que o Holocausto foi descortinado. O esforço para superar tal opróbrio começou com o pedido de perdão por parte do Papa João Paulo II, em nome de toda a Igreja católica, ao longo de todo o seu pontificado.

Não podemos deixar de notar o recrudescimento desse ideário de direita, nos países em que o mal-estar da sociedade contemporânea não consegue ser superado e onde a democracia liberal enquanto sistema político mostrou-se incapaz de propiciar melhorias no padrão de vida da população e de resolver problemas como a imigração, o desemprego, a violência e a miséria.

\section{REFERÊNCIAS}

BOBBIO, Norberto; MATTEUCCI, Nicola; PASQUINO, Gianfranco. Dicionário de Política. 5.ed. Brasília: EdUnB, 2000

CROUZET, Maurice (diretor). A época contemporânea: o mundo dividido. 1.ed. Rio de Janeiro: Bertrand Brasil, 1996

CROUZET, Maurice (diretor). A época contemporânea: o declínio da Europa. O mundo soviético. 1.ed. Rio de Janeiro: Bertrand Brasil, 1996

Dom Hélder Câmara. Disponível em http://www.domhelder.com.br. Acesso em 28 jul. 2005

Doutrina Integralista. Disponível em http://www.integralismo.com.br. Acesso em 28 jul. 2005

FACON, Patrick. Franco: os militares conduzem o general ao poder. História Viva. São Paulo: jun. 2004. p.70-72

FIORANI, Mario. Breve história do fascismo. 1.ed. Rio de Janeiro: Civilização Brasileira, 1963

GALLO, Max. O rei oferece o poder a Mussolini. História Viva. São Paulo: jun. 2004. p.64-66

LUNA, Fernando. Anauê! Livro sobre Ação Integralista Brasileira revela o dia-a-dia do fascismo no país. Veja. São Paulo: 18 nov. 1998. p.108-111

MAZOWER, Mark. Continente sombrio: A Europa no século XX. 1.ed. São Paulo: Companhia das Letras, 2001

MICROSOFT CORPORATION: Microsoft Encarta 2003. Redmond, 2002

POULANTZAS, Nicos. Fascismo e ditadura. [S.I:S.n] [1970] 
REIS FILHO, Daniel Aarão; FERREIRA, Jorge; ZENHA, Celeste (org). $O$ século $X X$ : o tempo das crises: revoluções, fascismos e guerras. 1.ed. Rio de Janeiro: Civilização Brasileira, 2000

TEIXEIRA DA SILVA, Francisco Carlos (coordenador) et alli. Enciclopédia de guerras e revoluções do Século XX: as grandes transformações do mundo contemporâneo. 1.ed. Rio de Janeiro: Elsevier, 2004

TRENTO, Angelo. Fascismo italiano. 1.ed. São Paulo: Ática, 1986 